\title{
Reinsurance Brokers and Advice Quality: Is There a Need for Regulation?
}

\author{
Michael Sonnenholzner ${ }^{1}$, Sebastian Friese $^{1,2}$ and J.-Matthias \\ Graf v. d. Schulenburg ${ }^{2}$ \\ ${ }^{1}$ Munich Re, Königinstrasse 107, 80802, Munich Germany. \\ ${ }^{2}$ Institute for Risk and Insurance, Leibniz University Hannover, Germany.
}

Brokers play an increasing role in the distribution of reinsurance. In order to analyse reinsurance brokers' advice quality, we employ a model in which a monopoly broker advises cedents to buy a particular one out of similar reinsurance policies that cost the same but differ in details. The broker decides on how much to invest in his advice quality and on the price to charge for his service. We find that the broker's advice quality is generally lower and the price for his service higher than in the social optimum, even in the presence of a potential new entrant.

The Geneva Risk and Insurance Review (2009) 34, 20-46. doi:10.1057/grir.2008.14

Keywords: reinsurance broker; advice quality; regulation

\section{Introduction}

Reinsurance brokers play a central role in the distribution of reinsurance products, especially in the U.S. and the U.K., and their share of the continental European market continues to increase as well. This increase also reflects the growth in offshore reinsurance markets such as Bermuda, which are almost entirely broker driven. At the same time, consolidation in the reinsurance broker market has increased tremendously over the last decade and created a highly concentrated market, with the top four companies accounting for about three-quarters of the total market. And further consolidation in the reinsurance broking sector is expected as big and mid-sized companies make acquisitions to fuel revenue growth and expansion into additional markets. The recent investigations into the U.S. reinsurance broker industry carried out by former New York State Attorney General E. Spitzer highlighted potential detrimental effects on the brokers' advice quality resulting from increased market power.

Motivated by concerns about the quality of insurance intermediation, the European Union (EU) announced directive 2002/92/EC, which became effective on 15 January 2005. The directive's aim is to harmonise the distribution of insurance within the EU's member countries and to protect 
customers both in the primary and reinsurance sector. Among other arrangements, the directive requires insurance and reinsurance intermediaries to "possess appropriate knowledge and ability, as determined by the home Member State of the intermediary". "In the example of Germany, the directive became effective as a national law on 22 May 2007.

The development towards increased market power in the reinsurance intermediation business and the directive of the EU gave us reason to have a closer look at the role of advice quality in the reinsurance intermediation business, which is the aim of this paper.

The model we employ is intended to isolate the effect of a reinsurance broker's advice quality on social welfare and on the division of the reinsurance market between brokers (broker market) and buying directly from a reinsurer or an underwriting agency ${ }^{2}$ (direct market). Therefore, we abstract from price differentials for similar reinsurance policies. This is in contrast to existing literature in this field, which associates the role of a broker with a price search service, what is certainly an important aspect. However, the focus of this paper shall be on the reinsurance broker's advice quality, not with regard to finding the cheapest reinsurance policy but to recommending the right policy that covers the cedent's needs best.

In our model there are two similar reinsurance policies in the market. Each policy is offered by several reinsurers who engage in Bertrand price competition (Bertrand, 1883). It is assumed that both reinsurance policies have the same price. However, they differ in some details that are not obvious to the cedents. The reason for the difference is treated as exogenous. We assume that cedents are equally distributed with regard to their ex-ante probabilities that a particular one of the available reinsurance policies is best for them. Those cedents who feel sufficiently sure as to which policy fits their needs best will buy directly from a reinsurer or an underwriting agency. The others consult a reinsurance broker who will sell them the reinsurance policy he recommends, however for a markup. The broker's advice will be correct with a certain probability, which we henceforth refer to as advice quality. The reinsurance broker can invest in his advice quality that is assumed to cause increasing and convex costs.

A monopoly reinsurance broker who is not subject to potential market entry by competitors will always offer an advice quality that is lower than in the social optimum. This is because the monopoly broker ignores the positive external effect of higher advice quality on the cedents' surplus. Furthermore,

\footnotetext{
${ }^{1}$ See directive 2002/92/EC of the European Parliament and of the Council, article 4(1).

2 Reinsurance underwriting agencies are acting on behalf of an affiliated or non-affiliated reinsurance company in the sense of an exclusive agent.
} 
he will also charge a price ${ }^{3}$ that is higher than in the social optimum. The reason for this is that the investment in advice quality is a fixed payment, which is sunk at the time when the broker sells his reinsurance policies. All in all, welfare in the situation of an uncontested monopoly reinsurance broker is strictly lower than in the social optimum. The first best welfare level can only be achieved by regulation of both the reinsurance broker's price and his advice quality. However, even if regulation is limited to advice quality as a policy instrument, welfare can still be increased in many situations.

We also look at situations where the incumbent reinsurance broker faces the threat of market entry by competitors. Even in such a situation the incumbent broker remains the only broker in the market in equilibrium. The intuition behind this result is that once a competitor enters the market Bertrand price competition will be triggered. As investments in advice quality are sunk at this stage, the incumbent reinsurance broker will undercut the new entrant by offering better advice quality or a lower price until he reaches a zero profit. This mechanism of fierce undercutting allows him to establish credible entry deterrence. The equilibrium price-advice quality combination offered by the contested incumbent broker will depend on the flexibility of price and advice quality once they have been chosen for the first time. We analyse the situations of full flexibility of both price and advice quality, flexibility of price but inflexibility of advice quality as well as inflexibility of both variables. Again, the resulting welfare level is always below the socially optimal welfare level. Only regulation of both price and advice quality can achieve the optimal welfare. However, in the case of full flexibility of both variables, even regulation of advice quality only is always welfare enhancing. This result also holds in the case of flexibility of price but inflexibility of advice quality for a broad range of parameter specifications. Only if both variables are inflexible, calling for a binding minimum advice quality is detrimental to social welfare.

Altogether, analysing the role of reinsurance brokers' advice on finding the reinsurance policy which fits a cedent's needs best provides two main insights: Firstly, a broker market as modelled in this paper will in general be characterised by a price which is too high and an advice quality which is too low in comparison with the social optimum. Secondly, even regulation that is restricted to improving advice quality can increase social welfare in many situations. This seems important as regulation of price may not be feasible and also not preferable in practice, at least in the context of a free market economy.

\footnotetext{
${ }^{3}$ Price in the context of the reinsurance broker shall denote the broker's markup only, not the total price of a reinsurance policy bought from a broker.
} 
However, regulating advice quality via a minimum training level may be a reasonable procedure in two out of three market situations that are looked at in the theoretical framework of this paper.

\section{Related literature}

There are already various papers that deal with insurance intermediaries and that mainly focus on the coexistence of insurance brokers and exclusive (dependent) agents in the market of primary insurance. The basic question is why brokers can survive in the market even though they are apparently more expensive (e.g. Joskow, 1973; Cummins and VanDerhei, 1979; and Barrese and Nelson, 1992) and thus seem to be inefficient. Two main branches can be identified in the literature. The first one tries to explain the brokers' existence with agency conflicts. The second branch focuses on value-adding services the broker provides to his clients.

Agency conflicts between insurers and agents are analysed by Marvel (1982), Grossman and Hart (1986) as well as Sass and Gisser (1989). Mayers and Smith Jr. (1981) confine themselves to a brief statement on the expected intensity of agency problems between the insurance company and the insurance agent, as well as the insurance agent and the policyholder.

The basic argument of Marvel (1982) is that exclusive dealing is a means to enforce supplier property rights. For example, an insurance company may invest in substantial advertising and pass on some of the costs to the distribution system via lower commissions. Then brokers have an incentive to sell policies from rival insurers who do not advertise and thus pay higher commissions. The author points out that using exclusive agents prevents such free riding and protects the insurer's investment in advertising.

A further theory explaining the apportionment of insurance distribution between brokers and exclusive agents is put forward by Sass and Gisser (1989). In contrast to Grossman and Hart (1986) as well as Marvel (1982), their argument is independent of incontractibles and supplier property rights and relates to reducing the agency costs inherent in commission contracts. The authors' starting point is the general share-contracting problem: a broker's sales effort determines the payoff of the insurers he represents. As the broker is only entitled to a share of the payoff (commission), he employs less effort than the insurers would. It is argued that switching the broker to be an exclusive agent for one particular insurer will induce him to provide a higher level of effort for this insurer than before.

The article by Kim et al. (1996) contains an empirical study which makes a systematic approach in order to identify the most important determinants of an 
insurer's choice between brokers and dependent agents. The analysis is tailored around contracting problems between insurers and agents, as well as insurers and clients. The empirical results of Kim et al. (1996) yield that the lines of insurance are the main driving force, whereby higher price, higher service policies appear to be sold predominantly by independent agents. The results also seem to validate the hypothesis of Mayers and Smith Jr. (1981) that insurers in close private ownership are more likely to expropriate policyholders, which makes them use brokers as a self-bonding device. Moreover, the results are consistent with the argument of Sass and Gisser (1989), whereupon higher geographic concentration argues for exclusive agents. Furthermore, advertising is also a significant factor in the sense of Marvel (1982) and Grossman and Hart (1986).

One limitation of the agency-theoretic models introduced above is that they do not take account of the clients' choice between the two distribution systems. Therefore, a different branch of theoretical literature has evolved which mainly looks at value-added services the broker provides to his clients. However, mixed empirical results are reported as to whether independent agents really do provide better service quality to their customers. An empirical analysis by Etgar (1976) finds that brokers do not necessarily provide better services in all dimensions (e.g. assistance in risk analysis, placing insurance applications or claim handling), but may even be worse than exclusive agents in some regards. Cummins and Weisbart (1977) get a similar result. On the other hand, empirical support for the hypothesis that brokers actually do provide a higher quality of service also exists. For example, Barrese et al. (1995) obtain this result on the basis of using complaint data in the context of private passenger automobile insurance. In the same line, Berger et al. (1997) find that the cost differential between independent and exclusive agents is more due to different service qualities than market imperfections.

Posey and Yavaş (1995) develop a search model where insurers and potential clients search for each other to form a match. Both insurers and clients differ in their costs of doing the search on their own and can either be a low or high search cost type. By using a broker, an insurance company can avoid incurring search costs but has to pay a commission instead. Clients and insurers decide independently which distribution system to use. Prices are exogenous in the sense that it is assumed that each of the two insurer types charges the accordant zero-profit price. Therefore, the nature of the model is not really one of price search but rather of finding a good match. This model is related to the one in this paper in the sense that it focuses on finding a good match between the insurance policy and a cedent's needs as well. However, in Posey and Yavaş (1995), the brokers' commission is exogenous and their advice quality is not modelled. Posey and Tennyson (1998) is an extension of Posey and Yavaş 
(1995) as price is now determined endogenously. A dynamic extension of the price search approach is by Seog (1999).

Another interesting aspect is highlighted by Venezia et al. (1999). In their model, the value-added service of brokers is not price search but a better claims service. This is because in contrast to dependent agents, they can threaten to switch their clients to a different insurer if a claim is not settled promptly and fairly. As a result, the authors obtain a separating equilibrium in which highrisk clients choose a broker whereas low-risk clients buy directly. Therefore, they argue that the observed cost differential may not be due to broker's inefficiency but rather due to self-selection of cedents.

Gravelle (1994) ${ }^{4}$ includes a section on brokers' advice quality. The resulting advice quality under the two different remuneration systems is analysed as well as the resulting welfare implications. Advice quality is modelled as the degree of a broker's understating the mismatch vis-à-vis a cedent in order to increase the probability of a sale. In other words, poor advice quality is equivalent to a broker not being truthful and talking a cedent into buying the policy even though he would be better off without insurance. As misrepresentations by the broker cannot be detected by clients, all brokers are dishonest under a commission system in order to maximise their expected revenue. Under a feefor-advice system, however, brokers give accurate advice. This is because false information about the insurance policy cannot increase the cedents' willingness to pay for advice.

Finally, a recent innovative approach of tackling the coexistence problem between exclusive agents and independent agents is by Seog (2005). The article presents a model, in which insurance firms compete in a Cournot-Nash game and choose between using exclusive agents or independent agents. Hereby it is assumed that employing exclusive agents causes high fixed costs and low variable costs while the opposite is true for relying on independent agents. Insurance firms can enter and exit the market as well as switch distribution systems without costs. Equilibrium is defined by a situation, in which no entry, exit or switching occurs. As a main result, it is found that coexistence of distribution systems is possible when insurers with independent agents are less efficient.

\section{The model}

We assume that there are two reinsurance policies $A$ and $B$ in the market. Each of the policies is offered by several different reinsurers who compete in prices

\footnotetext{
${ }^{4}$ Gravelle (1994) draws on two similar papers that are Gravelle (1991, 1993).
} 
(Bertrand competition). These two policies cost the same, basically cover the same risk but differ in details. In particular, the policies are characterised by different combinations of clauses. Depending on the individual situation of a cedent (e.g. structure of risk portfolio, liquidity situation, business strategy) various clauses are likely to be of different importance to different insurers. As we assume that the price of the two policies is the same, it seems plausible that a cedent will face a trade-off between a more favourable clause on a particular issue and a less favourable clause for another issue. For example, both reinsurance policies could provide property catastrophe excess of loss coverage. However, one policy is more generous regarding the definition of the event (e.g. storm event may last $48 \mathrm{~h}$ instead of $24 \mathrm{~h}$ ) but has higher thresholds for the proof, calculation or payment of claims.

\section{Cedents}

Cedents are split equally into two types: for the first group, reinsurance policy $A$ provides a higher expected utility. The opposite is the case for the second group. However, there is heterogenous information among cedents: some have a good assessment regarding what reinsurance policy to buy, whereas others only have a vague or no idea whether to choose $A$ or $B$. We assume that cedents arrive at these different probabilities because they are heterogenous with regard to their market knowledge or search costs. In order to model this situation, each cedent is assigned an $e x$-ante probability $\pi_{A}$ with which policy $A$ is the better one. In the spirit of Hotelling (1929), we assume that cedents are equally distributed with regard to $\pi_{A}$ on a line between 0 and $1 .{ }^{5}$ Thus, a cedent who is located at $\pi_{A}=1$ is completely sure that policy $A$ is better for him than policy $B$. Similarly, at $\pi_{A}=0$ buying $B$ is surely the best choice. However, all other cedents have a lower level of confidence as to which policy they should buy and a cedent with $\pi_{A}=1 / 2$ is absolutely unsure.

\section{Reinsurance brokers}

Cedents have the possibility to contact a reinsurer directly (or via an underwriting agency) and buy policy $A$ or $B$ for a price of $p_{A}$ or $p_{B}$, respectively. Alternatively, they can seek the advice of an independent reinsurance broker. The broker will provide a recommendation and sell the

\footnotetext{
${ }^{5}$ A similar approach can be found in Schlesinger and Graf von der Schulenburg (1991), where a spatial representation of consumer preferences is used for analyzing insurers' service quality.
} 
according reinsurance policy, however for a markup of $p_{b}$ in addition to the original price of the policy. The central issue in this paper is the probability $s$ with which the broker gives the correct recommendation: $\operatorname{Prob}\left(R_{i} \mid i\right)=s$, where $R_{i}$ denotes the event "broker recommends reinsurance policy $i$ " given that the cedent is of type $i$ with $i \in\{A, B\}$. For simplicity, we assume that the broker will recommend the unsuitable policy with probability $(1-s): \operatorname{Prob}\left(R_{i} \mid \bar{i}\right)=1-s$.

The broker is able to improve his advice quality by investing in the training of his staff. We assume that the training of newly hired employees causes significant initial costs, while an experienced employee keeps up to date mainly through his everyday activities and causes only little training costs. Therefore, we model the investment in advice quality as fixed costs. Once costs rise from 0 for the first time, the broker incurs strictly increasing and convex costs $C(s)$ for improving his signal quality $s$, which will be pointed out in more detail later on.

In the remainder of the article we use the following notation: $V_{i j}$ describes the valuation of cedent type $i$ for policy $j$. For example, $V_{A A}$ characterises the expected utility a cedent of type $A$ derives from getting the correct reinsurance policy $A$, whereas $V_{A B}$ represents the expected utility of cedent type $A$ from getting the wrong policy $B$, with $V_{A A}>V_{A B}$. Furthermore, we assume symmetry, that is $V_{A A}=V_{B B}, V_{A B}=V_{B A}$ and $p_{A}=p_{B}$. For notational convenience, we define $a:=V_{A A}-V_{B A}$.

\section{Monopoly reinsurance broker without threat of new entry}

In this section we compute the price and the signal quality of a monopoly reinsurance broker when no new entry in the broker market is possible. Then we compare the results to the socially optimal price and signal quality (which would be chosen by a benevolent social planner).

\section{Monopoly broker's price and signal quality}

A rational cedent with $\pi_{A}>1 / 2$ who buys directly from a reinsurer (or from an underwriting agency) will buy reinsurance policy $A$. Then his expected utility is

$$
\begin{aligned}
E U^{d} & =\pi_{A}\left(V_{A A}-p_{A}\right)+\left(1-\pi_{A}\right)\left(V_{B A}-p_{A}\right) \\
& =\pi_{A} a+V_{B A}-p_{A} .
\end{aligned}
$$

If $\pi_{A}<1 / 2$, the cedent will buy policy $B$, which yields an expected utility of:

$$
\begin{aligned}
E U^{d} & =\left(1-\pi_{A}\right)\left(V_{B B}-p_{B}\right)+\pi_{A}\left(V_{A B}-p_{B}\right) \\
& =\left(1-\pi_{A}\right) a+V_{A B}-p_{B} .
\end{aligned}
$$




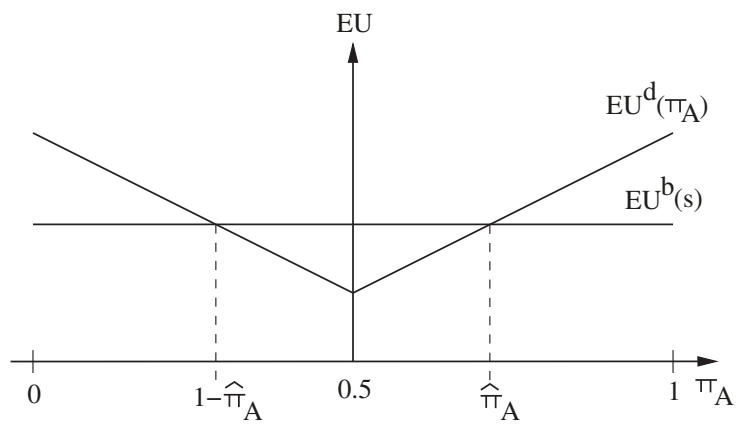

Figure 1. Broker clients' and direct clients' expected utility, represented by $E U^{b}(s)$ and $E U^{d}\left(\pi_{A}\right)$, respectively, for fixed parameters $s$ (advice quality), $a$ (advantage of correct advice) and $p_{b}$ (price of broker).

The cedent is indifferent at $\pi_{A}=1 / 2$ and either of the two formulas for $E U^{d}$ will describe the cedent's expected utility correctly. A graphical representation of $E U^{d}$ as a function of $\pi_{A}$ is given in Figure 1. It can be seen that $E U^{d}$ has a minimum at $\pi_{A}=0.5$, which represents the point of indifference between $A$ and $B$. As $\pi_{A}$ grows larger (right half of graph in Figure 1), $E U^{d}$ increases due to a higher probability of buying the correct policy $A$. The symmetrical case is true for values of $\pi_{A}<0.5$ (left half of graph in Figure 1), where the cedent will buy policy $B$. The symmetry of Figure 1 stems from the before-mentioned symmetry of valuations and prices.

When a cedent buys from a broker, his expected utility is

$$
\begin{aligned}
E U^{b}= & \pi_{A}\left[s\left(V_{A A}-p_{A}\right)+(1-s)\left(V_{A B}-p_{B}\right)\right] \\
& +\left(1-\pi_{A}\right)\left[s\left(V_{B B}-p_{B}\right)+(1-s)\left(V_{B A}-p_{A}\right)\right]-p_{b} \\
= & s a+V_{B A}-p_{A}-p_{b} \text { (due to symmetry assumption). }
\end{aligned}
$$

Equating $E U^{d}$ and $E U^{b}$ and solving for $\pi_{A}$ yields the probability $\hat{\pi}_{A}$ of the marginal cedent who is indifferent between the broker and buying directly from the reinsurer:

$$
\hat{\pi}_{A}=s-\frac{p_{b}}{a} .
$$

This equation shows that the number of cedents buying from the broker is higher, the higher his signal quality $s$, the lower his price $p_{b}$ and the higher the cedents' advantage $a$ from buying the correct policy. Because of the symmetry assumption, it holds that $\hat{\pi}_{B}=1-\hat{\pi}_{A}$. A graphical representation is given in Figure 1 . Cedents whose ex-ante probability $\pi_{A}$ is between $1-\hat{\pi}_{A}$ and $\hat{\pi}_{A}$ buy 
from the broker, as their expected utility $E U^{b}(s)$ will be higher than if they buy from a reinsurer directly. This would give them an expected utility of only $E U^{d}\left(\pi_{A}\right)$. It is noteworthy that expected utility when buying from the broker $E U^{b}(s)$ is not a function of $\pi_{A}$ but of $s$. Therefore, $E U^{b}(s)$ is a flat line in Figure 1. A higher $s$ would shift the line upwards, thus leading to higher broker client surplus and therefore also raising aggregate cedent surplus.

In the model we assume that the cedent always buys the policy the broker recommends. Therefore, the question arises under what circumstances a cedent whose ex-ante probability favors policy $A\left(\pi_{A}>0.5\right)$ is willing to accept a broker's recommendation to buy policy $B$. Applying Bayes' rule yields that this is only the case if $s>\pi_{A}$. As $\hat{\pi}_{A}=s-\left(p_{b} / a\right)<S$, this condition is always satisfied.

Because of symmetry, the overall demand for the broker's service is $2\left(\hat{\pi}_{A}-\right.$ $(1 / 2))$. The demand and the costs of the signal quality enter the profit function $G$ of the broker which is

$$
G=2\left[s-\frac{p_{b}}{a}-\frac{1}{2}\right] p_{b}-C(s) .
$$

To make the problem interesting, we assume that there is a region in the $\left(s, p_{b}\right)$ space where the monopoly broker makes a strictly positive profit. This implies that costs $C(s)$ will rise slowly enough as advice quality is increased from $s=1 / 2$. Otherwise, no broker would be willing to enter the market. The monopoly broker will maximise $G$ via the choice of $s$ and $p_{b}$ under the constraints of $p_{b} \geqslant 0$ and $(1 / 2) \leqslant s \leqslant 1$.

In order to find a solution for the constrained maximisation problem, we first solve the unconstrained maximisation problem. Then we analyse the assumptions necessary to interpret the solution of the unconstrained problem as the solution of the constrained problem.

Solving the first-order conditions of the unconstrained problem yields the following equations:

$$
\begin{aligned}
& C^{\prime}(s)=a\left(s-\frac{1}{2}\right) . \\
& p_{b}=\frac{1}{2} a\left(s-\frac{1}{2}\right) .
\end{aligned}
$$

In order to find a unique absolute maximum under the unconstrained problem, $G$ must be strictly concave. The corresponding Hessian of $G$ is

$$
H=\left[\begin{array}{ll}
-C^{\prime \prime}(s) & 2 \\
2 & -\frac{4}{a}
\end{array}\right] .
$$


For strict concavity, the Hessian must be negative definite everywhere. This is satisfied, if $-C^{\prime \prime}(s)<0$ and $(4 / a) C^{\prime \prime}(s)-4>0$ which is equivalent to $C^{\prime \prime}(s)>a$. It can be seen that $C(s)$ has to be sufficiently convex, as determined by $C^{\prime \prime}(s)>a$, in order to guarantee strict global concavity of $G$. However, assuming convex costs seems to be quite plausible, because improving the signal from mere guessing is relatively cheap, while achieving a perfect signal can be thought of being infinitely expensive, with increasing marginal costs in between.

As a next step we assume global strict concavity of $G$ and try to replace the constrained maximisation problem by an unconstrained one. Inspection of (4) shows that $p_{b} \geqslant 0$ will always be satisfied as $a \geqslant 0$ and $s \geqslant 1 / 2$. From (3) follows that $s \geqslant 1 / 2$ will always be satisfied as well, because we assume that $C^{\prime}(s) \geqslant 0$ and $a>0$. Therefore, the constraints of the maximisation problem can be reduced to the condition $s \leqslant 1$. Then we plug (4) into (2) and obtain

$$
\hat{G}=\frac{1}{2} a\left(s-\frac{1}{2}\right)^{2}-C(s),
$$

which gives a more condensed version of the unconstrained problem in only one variable $s$. It becomes clear that an optimal $s<1$ will occur, if $C(s)$ is convex enough as $s$ converges to one. In the real world, it may be considered plausible that $\lim [C(s)]_{s \rightarrow 1}=\infty$, as described above. Therefore, the analysis to follow in this paper will be based on the following assumption:

Assumption 1 Regarding the cost function $C(s)$ it holds that $C^{\prime \prime}(s)>a$ and $\lim [C(s)]_{s \rightarrow 1}=\infty$. Furthermore, $a>0, C^{\prime}(s) \geqslant 0, C(1 / 2)=0, C^{\prime}(1 / 2)=0$ and $C(s)<(1 / 2) a(s-(1 / 2))^{2}$ on some interval $s \in((1 / 2) ;(1 / 2)+\varepsilon)$, with $\varepsilon>0$.

Altogether, Assumption 1 guarantees global concavity of the monopoly broker's profit function (2) and an interior solution for the profit maximising $s$. In order to make the problem interesting, the last condition ensures that $C(s)$ rises slowly enough as $s$ increases from $s=1 / 2$ for the monopoly broker's profit function to be strictly positive in some region of its domain.

After having motivated Assumption 1, we are ready to interpret the solutions to the unconstrained maximisation problem as being identical with the solutions to the relevant constrained maximisation problem: the intuition behind (3) is that the optimal advice quality of the monopoly broker, which shall be denoted $s^{M}$, can be found by equating the marginal costs of a quality increase $C^{\prime}(s)$ to the marginal increase in turnover which is the term $a(s-(1 / 2))$ on the right hand side. To see this, let turnover be defined by $T\left(p_{b}, s\right)=2\left(s-\left(p_{b}\right)\right.$ a) $-(1 / 2)) p_{b}$. The total differential is $\mathrm{d} T=\left(\partial T / \partial p_{b}\right) \mathrm{d} p_{b}+(\partial T / \partial s) \mathrm{d} s$. However, $\partial T / \partial p_{b}=\partial G / \partial p_{b}=0$ due to the first-order condition. This yields $\mathrm{d} T /$ $\mathrm{d} s=2 p_{b}=a(s-(1 / 2))$, if evaluated at the optimal price $p_{b}$. It becomes clear that 
the monopoly broker ignores the positive externality of increased advice quality on the cedents' surplus. Furthermore, it follows from (4) that the monopoly broker charges a strictly positive price $p_{b}$ if $a>0$ and $s>1 / 2$.

\section{Socially optimal price and signal quality}

The socially optimal signal quality maximises welfare $W\left(s, p_{b}\right)$ subject to $p_{b} \geqslant 0$ and $(1 / 2) \leqslant s \leqslant 1$. Social welfare is the sum of the surplus of the clients who buy directly, the broker's clients and the broker:

$$
\begin{aligned}
W\left(s, p_{b}\right)= & 2 \int_{\hat{\pi}_{A}\left(s, p_{b}\right)}^{1}\left(\pi_{A} a+V_{B A}-p_{A}\right) \mathrm{d} \pi_{A} \\
& +2\left(\hat{\pi}_{A}\left(s, p_{b}\right)-\frac{1}{2}\right)\left(s a+V_{B A}-p_{A}-p_{b}\right) \\
& +2\left(\hat{\pi}_{A}\left(s, p_{b}\right)-\frac{1}{2}\right) p_{b}-C(s) \\
= & s^{2} a-s a+a-\frac{p_{b}^{2}}{a}+V_{B A}-p_{A}-C(s) .
\end{aligned}
$$

We abstract from including the reinsurance companies' profit in the welfare function. This is because we assume that each of the reinsurance policies $A$ and $B$ is offered by several reinsurers who engage in Bertrand price competition and thus always make a zero profit.

As before regarding the broker's profit function, we solve the unconstrained maximisation problem first. Taking the derivatives of $W$ with respect to $s$ and $p_{b}$ yields:

$$
\begin{gathered}
\frac{\mathrm{d} W}{\mathrm{~d} s}=2 a s-a-C^{\prime}(s)=0, \\
\frac{\mathrm{d} W}{\mathrm{~d} p_{b}}=-\frac{2 p_{b}}{a}=0 .
\end{gathered}
$$

It follows that

$$
\begin{aligned}
C^{\prime}(s) & =2 a\left(s-\frac{1}{2}\right) \quad \text { and } \\
p_{b} & =0 .
\end{aligned}
$$

This shows that the constraint regarding $p_{b}$ is not binding. As we assume $C^{\prime}(s) \geqslant 0$ and $a>0$, the constraint $s \geqslant 1 / 2$ is not binding either. Therefore, the 
only constraint that cannot be guaranteed at this point is $s \leqslant 1$. Let $s^{*}$ denote the socially optimal signal quality and $\hat{s}$ the solution of the unconstrained maximisation problem as represented by (6). Then we have

$$
s^{*}= \begin{cases}\hat{s}, & \text { if } \hat{s} \leqslant 1, \\ 1, & \text { if } \hat{s}>1 .\end{cases}
$$

As we are interested in finding a unique absolute maximum of $W$, we compute the accordant Hessian, which is

$$
H=\left[\begin{array}{ll}
2 a-C^{\prime \prime}(s) & 0 \\
0 & -\frac{2}{a}
\end{array}\right] .
$$

It turns out that $W\left(s, p_{b}\right)$ is globally strictly concave, if $C^{\prime \prime}(s)>2 a$ for each $s$. Thus, we make the following assumption that will also be implied throughout this paper:

Assumption 2 The costs of investing in advice quality $C(s)$ are convex enough to guarantee global concavity of the social welfare function (5), which requires $C^{\prime \prime}(s)>2 a$.

Then the following result can be obtained:

Proposition 1 The monopoly broker will provide a socially suboptimal signal quality, $s^{M}<s^{*}$, and charge a price which is higher than in the social optimum.

Proof The result follows directly from comparing (3), (4) and (6).

It holds that $p_{b}=0$ in the social optimum, because in (2) we abstract from any marginal variable costs associated with providing the broker service.

\section{Incumbent broker with threat of new entry}

In practice there are no substantial barriers to entry in the reinsurance broker market. Therefore, this section looks at the case when the incumbent broker is not shielded from potential competition by outsiders who may enter the market. The objective is to analyse whether the threat of new entry can induce the incumbent broker to offer a better price and signal quality than the suboptimal levels, which prevailed in the previous section. In order to do that it needs to be defined how competition works once a newcomer enters 
the broker market. The following game structure is used as a framework for the analysis:

1. The incumbent broker chooses a price-advice quality combination $\left(p_{b}^{I 1}, s^{I 1}\right)$ and pays $C\left(s^{I 1}\right)$.

2. A potential entrant decides whether to enter the broker market. If there is no entry, the game continues with stage 4.

3. If entry occurred, the incumbent broker and the new entrant engage in Bertrand style competition by choosing their price $p_{b}$ and their advice quality $s$ simultaneously:

(a) entrant: $p_{b}^{E}, s^{E}$, payment of $C\left(s^{E}\right)$

(b)incumbent: $p_{b}^{I 2}, s^{I 2}$, payment of $C\left(s^{I 2}\right)-C\left(s^{I 1}\right)$, if $s^{I 2}>s^{I 1}$

4. Cedents buy and payoffs are realised. If the incumbent and the entrant offer price-advice quality combinations which offer the same expected utility for cedents, the market is assumed to split evenly.

Bertrand competition as opposed to Cournot competition seems to be appropriate in this context. This is because reinsurance brokers provide an intangible service upon request rather than producing countable quantities of some sort of product.

Different equilibria of the game arise depending on whether the circumstances in the reinsurance broker market allow changes of $p_{b}$ and $s$ after these variables were chosen by a broker for the first time. This is relevant for the incumbent only, because he makes a choice concerning his price and advice quality in stage 1 and may want to change his choice in stage 3, depending on whether entry has occurred. We look at three cases: (1) Full flexibility of both $p_{b}$ and $s$. In this case, the incumbent can change both variables in stage 3 of the game at will. (2) Flexibility of $p_{b}$ but inflexibility of $s$. In this case, the incumbent is committed to the advice quality chosen in stage 1 of the game: $s^{I 2}=s^{I 1}$. The inability to increase advice quality quickly could result from the fact that training of existing staff and hiring staff with a higher experience/ education level takes quite a substantial amount of time. This restriction is mainly relevant for the incumbent, as a potential new entrant can engage in hidden preparatory actions before entering the market. (3) Inflexibility of both $p_{b}$ and $s$. Then, the incumbent is fully committed to both variables as chosen in stage $1: s^{I 2}=s^{I 1}$ and $p_{b}^{I 2}=p_{b}^{I 1}$.

The equilibria will be outlined below with the help of Figure 2, which shows an example of a contour plot of a monopoly broker's profit function according to (2). The horizontal axis represents signal quality $s$ and the vertical axis price $p_{b}$. Point $M$ marks the peak of the profit function, whereas the outer-most contour depicts the zero-profit locus. The sloped line which is tangent to the zero-profit locus at $T$ and its parallels show broker clients' indifference curves according to (1). The socially optimal contract is represented by point $W$. 


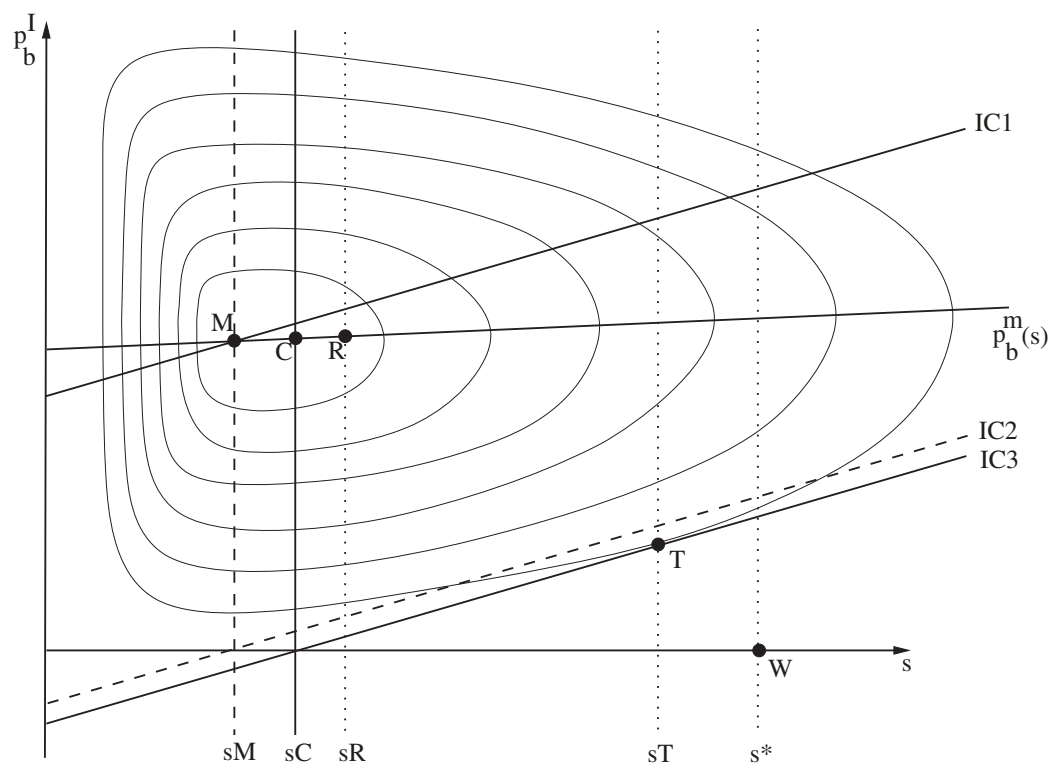

Figure 2. Contour plot (stylized) of a monopoly broker's profit function and broker clients' indifference curves $\left(I C_{1, \ldots, 3}\right)$. The line $p_{b}^{m}(s)$ describes the broker's profit-maximizing price $p_{b}^{m}$ for each given minimum advice quality $s$, as established in lemma 1 . Point $M$ marks the profit maximum and will be chosen in equilibrium by an incumbent monopoly broker who is flexible with regard to price and advice quality. The corresponding equilibrium advice quality is $s^{M}$. Point $C$ describes the equilibrium when the incumbent broker is only flexible with regard to price (associated equilibrium advice quality $s^{C}$ ). Point $T$ is the point of tangency between the cedents' indifference curve $I C_{3}$ and the zero-profit locus and represents the equilibrium when the incumbent broker is inflexible with regard to both price and advice quality. Point $W$ marks the socially optimal combination of price $\left(p_{b}=0\right)$ and advice quality $\left(s=s^{*}\right)$. Point $R$ is the outcome if the incumbent broker is regulated to offer that particular level of advice quality, which maximises social welfare when allowing the broker to choose the profit maximising price. This situation is described in more detail in the context of Figure 3.

Before proceeding with the analysis of the equilibria of the game, we prove the following lemma, which will turn out to be useful later on:

Lemma 1 The monopoly broker's profit-maximising price $p_{b}^{m}$ under the constraint of a binding minimum advice quality $\bar{s}$ is described by $p_{b}^{m}(\bar{s})=(1 / 2) a \bar{s}-(1 / 4) a$. In Figure 2, this relationship is represented by the line through $M, C$ and $R$. Starting from the monopoly contract $M$, broker clients' surplus and therefore total cedent surplus is increasing in $\bar{s}$ when moving along $p_{b}^{m}(s)$. 
Proof The first part of the lemma is obtained immediately by maximising (2) over $p_{b}$ for any given $\bar{s}$. Regarding the second part of the lemma, it holds that $\mathrm{d} p_{b}^{m} / \mathrm{d} s=(1 / 2) a$, while the steepness of the broker clients' indifference curves according to (1) is $a$. Thus, the broker clients' surplus is increasing when moving along $p_{b}^{m}(s)$ to the right of $M$. As a consequence, total cedent surplus will be increasing as well, because direct clients will only become broker clients if they are better off.

\section{Full flexibility of $\boldsymbol{p}_{\boldsymbol{b}}$ and $\boldsymbol{s}$}

The equilibrium of the game is solved for via backward induction and leads to the following result:

Proposition 2 If there is full flexibility of $p_{b}$ and $s$, the equilibrium of the game is as follows: The incumbent broker will charge the monopoly price and provide the monopoly advice quality $s^{M}$ which is represented by point $M$ in Figure 2. The potential competitor will not enter the market.

Proof In stage 2, the entrant will only enter, if he ends up with a positive profit. If both $p_{b}$ and $s$ can be changed freely, Bertrand competition in $s$ and $p_{b}$ is triggered by the entry. The costs of advice quality $C\left(s^{I 1}\right)$ the incumbent paid in stage 1 are sunk in stage 3 . However, the costs of the entrant's advice quality and the incumbent's incremental advice quality are not sunk yet and thus still relevant for their decision. Therefore, the process of anticipated undercutting in stage 3 will end at point $T$. At this point, the entrant can no longer attract cedents with a contract they prefer to $T$ without incurring a loss. The incumbent would even be willing to undercut his rival beyond $T$ as long as he can achieve a positive turnover in order to recover at least part of his sunk entry costs $C\left(s^{I 1}\right)$. Under these circumstances, entering in stage 2 is never profitable. Therefore, the incumbent broker will not change his behaviour in stage 1 due to a potential entrant but charge the monopoly price-advice quality combination $\left(p_{b}^{M}, s^{M}\right)$ at point $M$.

The result shows that the power of unleashed Bertrand competition together with sunk entry costs is strong enough to deter entry. This holds regardless of the incumbent broker's offer in stage 1 , even if it is the monopoly $\left(p_{b}, s\right)$ combination at $M$. Suboptimal advice quality still prevails just as if there was no potential competitor who could enter the market.

\section{Full flexibility of $\boldsymbol{p}_{\boldsymbol{b}}$ but $\boldsymbol{s}$ cannot be changed}

If $s$ can no longer be changed after the incumbent has chosen it, the power of Bertrand competition as a weapon to deter entry is weakened somewhat. 
An inflexible advice quality is quite plausible, because further training of a broker takes time. On the other hand, employing a lower advice quality on purpose may be possible, but under Bertrand competition only better quality is relevant.

Proposition 3 If there is full flexibility of $p_{b}$ but $s$ cannot be changed after it has been chosen by the incumbent in stage 1, the equilibrium of the game is as follows:

1. If the cedents' indifference curve through $s^{M}$ and $p_{b}=0\left(I C_{2}\right.$, Figure 2) does not cut through the zero-profit locus of the incumbent broker's profit function, he will charge the monopoly price and provide the monopoly advice quality $s^{M}$ which is represented by point $M$ in Figure 2.

2. If the cedents' indifference curve through $s^{M}$ and $p_{b}=0\left(I C_{2}\right.$, Figure 2$)$ does cut through the zero-profit locus of the incumbent broker's profit function, he will offer a price and advice quality $s^{C}$ as represented by point $C$. If $a>0$, contract $C$ is characterised by a higher advice quality, a higher price and a higher cedent surplus than contract $M$.

In both cases, the potential competitor will not enter the broker market.

Proof Suppose the incumbent broker has chosen $M$ in stage 1 and is now committed to the corresponding advice quality which shall be denoted $s^{M}$. However, he can still engage in Bertrand competition using $p_{b}$ to undercut a new entrant.

Entering the market with a worse advice quality than $s^{M}$ is never attractive for a newcomer. As the incumbent's entry costs in the form of investments in advice quality $C\left(s^{I 1}\right)$ are sunk in stage 3, the limit of the incumbent's undercutting would be offering $s^{I 2}=s^{M}$ and a price $p^{I 2}$ of 0 which is equivalent to 0 turnover. The corresponding indifference curve of the cedents is $I C_{2}$ in Figure 2, which goes through $p_{b}=0$ and $s=s_{M}$. The cedents' indifference curves will always have a positive slope as long as $a>0$. Attracting cedents away from the incumbent broker would therefore require the entrant to charge a negative price. This will provoke a loss for the entrant.

On the other hand, entering with a better advice quality than the incumbent broker might be profitable. Suppose again that the incumbent broker offers $M$. As before, maximum undercutting under Bertrand competition will lead the incumbent to end up offering $s^{I 2}=s_{M}$ and $p_{b}^{I 2}=0$. However, if the corresponding indifference curve $I C_{2}$ cuts through the zero-profit locus (as in Figure 2), the entrant can offer a contract which is just marginally below this indifference curve but above the zero-profit locus. Doing so will allow the entrant to attract all cedents and make a profit, whereas the incumbent would end up with a loss of $C\left(s^{I 1}\right)$. Therefore, the incumbent broker will anticipate this outcome when choosing his offer in stage 1 and try to deter entry in stage 2 . In order to do that 
the incumbent has to choose an advice quality $s^{I 1}$ which is just high enough to prevent an entrant from making positive profits, if Bertrand competition forces the incumbent to set $p_{b}^{I 2}=0$ in stage 3. As depicted in Figure 2, the lowest possible and therefore profit-maximising advice quality $s^{C}$ for which this condition holds is determined by the intersection of the horizontal axis at $p_{b}=0$ and indifference curve $I C_{3}$, which is just tangent to the zero-profit locus at point $T$. Then, the incumbent broker maximises his profit at the resulting advice quality $s^{C}$, which leads to point $C$.

As a result, the equilibrium is characterised by the incumbent broker offering $C$ in stage 1 and the entrant deciding not to enter in stage 2, if the relevant indifference curve $I C_{2}$ cuts through the zero-profit locus as described above. If not, the incumbent broker will offer contract $M$ in stage 1 and entry will not occur either. It follows directly from Lemma 1 that $C$ entails a higher price, a higher advice quality and higher cedent welfare than $M$, if $a>0$.

\section{Neither $\boldsymbol{p}_{\boldsymbol{b}}$ nor $\boldsymbol{s}$ can be changed}

Proposition 4 If there is no flexibility regarding both $p_{b}$ and $s$ after the variables have been chosen by the incumbent in stage 1, the equilibrium of the game is as follows: the incumbent broker will offer a zero-profit contract as represented by $T$ in Figure 2. The potential competitor will not enter the broker market.

Proof Suppose that the incumbent broker in stage 1 chooses any other contract within or on the zero-profit locus apart from $T$. Then, a new entrant could attract all cedents by offering a contract that makes them better off but is still profitable. There would be no possibility for the incumbent broker to react. As a consequence, he has to fully anticipate this situation already in stage 1. As the indifference curves of the broker clients through $T$ represent their maximal surplus subject to zero profit, $T$ is the only contract the incumbent broker can offer in order to deter entry.

The intuition behind this result is that the power of Bertrand competition as a threat to deter entry is completely lost. In the example of Figure 2, advice quality $s^{T}$ is again closer to but still below the social planner's level $s^{*}$.

\section{Policy implications}

As shown in the previous section, in equilibrium there will always be just one reinsurance broker in the market. However, the contract offered by this incumbent broker depends on the flexibility of price $p_{b}$ and advice quality $s$ and points $M, C$ or $T$ may prevail as a result. This section deals with the question, if and how the incumbent broker should be regulated under these circumstances. 


\section{Advantageousness of regulation}

Regulation is reasonable if it increases social welfare. The first best level of welfare shall be defined as being the maximum attainable sum consisting of the broker clients' surplus, the direct clients' surplus and the broker's profit. Point $W$ in Figure 3 represents the first best level of welfare on the vertical axis and the associated advice quality on the horizontal axis. Points $W, T, M$ and $C$ in Figure 3 correspond to the respective points in Figure 2. The same is the case with $R$ whose role will be explained below.

Social welfare in any market outcome, with or without threat of entry, is always below the first best level of social welfare. In terms of the graphical example given in Figures 2 and 3, the welfare associated with $M, C$ and $T$ is always smaller than the first best level of welfare as represented by $W$. Due to Assumption 2, $W\left(p_{b}, s\right)$ is strictly concave with a unique absolute maximum at point $W$. Because of Assumption 1, it holds that $s>1 / 2$ for each point $M, C$ and $T$ which requires the incumbent reinsurance broker to charge a price $p_{b}>0$ in order to achieve at least zero profit. Therefore, $W$ never coincides with either $M, C$ or $T$, as each of these points is associated with a $p_{b}>0$, while $W$ is always associated with $p_{b}=0$.

It follows that regulating the incumbent broker always offers the possibility to achieve a higher social welfare. This raises the question of how the incumbent broker should be regulated. Basically there are two variables which can be influenced by the regulator in order to increase social welfare: price $p_{b}$ and advice quality $s$.

\section{Regulation using $\boldsymbol{s}$ and $\boldsymbol{p}_{\boldsymbol{b}}$}

As shown before, in a market outcome the monopoly broker will always charge a strictly positive price, while in the social optimum the broker's price is 0 . Thus, the first best level of social welfare can only be achieved by regulating both the broker's price $p_{b}$ and advice quality $s$. However, the downside of doing so is that a regulated price $p_{b}=0$ will inflict losses upon the monopoly broker which need to be covered somehow. As suggested by Gravelle (1991), this could be done by a lump sum tax which is just high enough to cover the monopoly broker's expenses on advice quality.

Another possibility is to choose $T$ instead of $W$ as a regulation goal. In this case, the monopoly broker makes zero profit. When there is total inflexibility of both $p_{b}$ and $s$, this result will prevail as a market outcome anyway and no further regulatory action needs to be taken.

\section{Regulation using $\mathbf{s}$ only}

Even though only regulating both $p_{b}$ and $s$ is capable of securing the first best level of social welfare, using $p_{b}$ as a policy instrument for regulation might not be possible for political or technical reasons. 


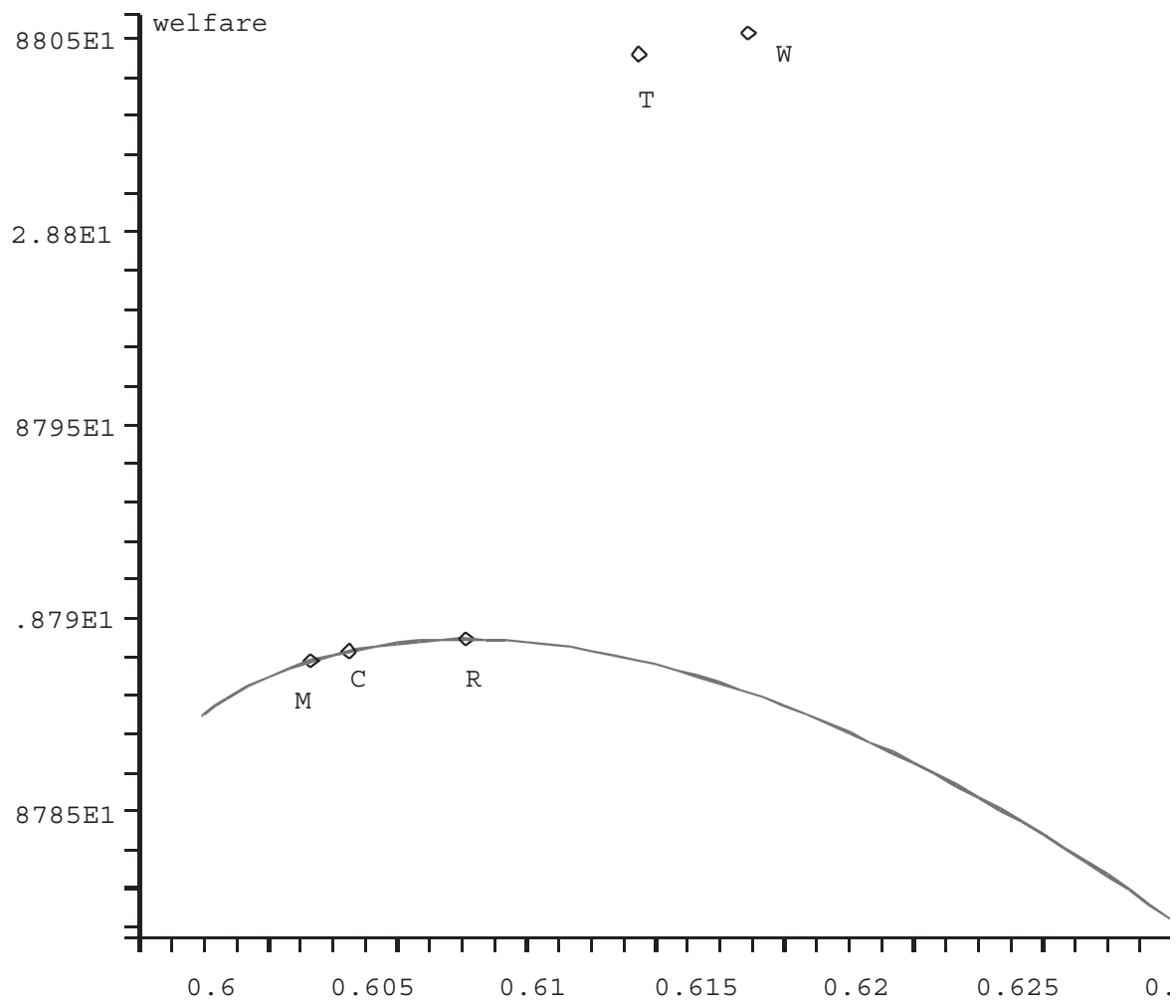

Figure 3. Different levels of social welfare are attainable under different competition situations. Point $W$ marks the maximum social welfare and the associated advice quality. Point $T$ represents welfare and advice quality in the equilibrium situation when the incumbent broker is inflexible with regard to both price and advice quality. Point $M$ represents the equilibrium situation when the incumbent broker is flexible with regard to both price and advice quality, while point $C$ represents equilibrium when price is flexible but advice quality is not. All points correspond to the respective points in Figure 2. The concave line through $M, C$ and $R$ represents the resulting social welfare when a regulator binds a "type $M$ " or "type $C$ " incumbent broker to offer the corresponding advice quality as a minimum, but the broker is still free to choose the profit maximising price. In such a situation, point $R$ marks the maximum attainable welfare level ("second best").

If there are reasons which prevent $p_{b}$ from being used as a regulation instrument, it follows that regulating $s$ only can never achieve the first best level of social welfare. The question arises how at least a second best regulation could be implemented. When the regulator prescribes a binding $s$, the monopoly broker will charge the corresponding profit-maximising price $p_{b}^{m}(s)$ as described by Lemma 1. The concave line in Figure 3 shows the social welfare associated with such a regulated $s$, when the monopoly broker charges the corresponding price $p_{b}^{m}(s)$. Point $R$ marks the maximum attainable social 
welfare and the corresponding advice quality $s^{R}$ in the case where only $s$ is regulated. Therefore, we call the associated welfare level second best optimal.

Proposition 5 The advice quality associated with $R$, denoted by $s^{R}$, is always higher than the advice quality associated with $M$, denoted by $s^{M}: s^{R}>s^{M}$.

Proof Starting from point $M$, it follows from Lemma 1 that the monopolist will move along $p_{b}^{m}(s)=(1 / 2) a s-(1 / 4) a$ when prescribing a binding $s$ with $s=s^{M}+\varepsilon$, with $\varepsilon>0$. However, $\partial G / \partial s^{M}=0$ and $\partial G / \partial p^{M}=0$ ((3) and (4)). Therefore, it holds that $\mathrm{d} G / \mathrm{d} s=0$ for a marginally small $\varepsilon$. Let $Q$ denote total cedent surplus, being the sum of broker and reinsurer clients' surpluses. Then, total welfare is represented by $W\left(s, p_{b}^{m}(s)\right)=G\left(s, p_{b}^{m}(s)\right)+Q\left(s, p_{b}^{m}(s)\right)$. Lemma 1 shows that $\mathrm{d} Q / \mathrm{d} s>0$ at point $M$. Thus, $\mathrm{d} W / \mathrm{d} s>0$.

The proposition shows that in the situation where $M$ is the market outcome, either with or without threat of entry, regulation is welfare enhancing even if it is limited to $s$ as a regulation instrument. This is because a higher $s$ is always advantageous for the cedents, taking into account that the broker sets his price along the profit maximising path $p_{b}^{m}(s)$ as described by Lemma 1 .

Regulation of $s$ only may also improve welfare in a situation where $C$ is the market outcome, as shown in Figure 3. However, it is difficult to tell analytically if $C$ could also be to the right of $R$. This is because $C$ is determined via the tangency condition at $T$ and $C$ 's relative position with regard to $R$ depends critically on the shape of the zero-profit contour as depicted in Figure 2. This zero-profit contour is driven by the shape of $C(s)$ that may take on unlimited different forms. Therefore, we have no universal analytical rule at hand under what circumstances $s^{C}$ could be equal to or larger than $s^{R}$, thus rendering the regulation of a binding minimum $s$ pointless. However, extensive simulations with a family of cost functions of the form $C(s)=k(s-0.6)^{z}$ yield that $s^{C}<s^{R}$ generally holds true. Only when $k$ grows very large or $z$ grows small, we obtain $s^{C}=s^{R}$ in the limit. Details can be found in the appendix. This shows that regulation of $s$ in this context can be seen to be welfare increasing at least in a broad range of specifications.

However, if $T$ is the market outcome, increasing $s$ via regulation is never useful. This is because the monopoly broker will move away from the point of tangency $T$ on the zero-profit contour. Therefore, social welfare will be smaller than at $T$ because the broker's profit is still 0 whereas cedent surplus decreases.

\section{Conclusion}

This paper analyzes the question of using a reinsurance broker or buying directly from a reinsurer under the aspect of advice quality. Because of 
heterogeneity regarding search costs or other reasons, cedents are assumed to arrive at different ex-ante probabilities that a particular one out of a range of similar reinsurance policies fits their needs best. Cedents can buy directly from a reinsurer or consult a reinsurance broker who will give them advice which reinsurance cover from the available ones is best for them. However, this service comes at a cost, as the broker will sell the client the recommended policy at a markup. His advice is of a particular quality, which is represented by the probability that he recommends the correct reinsurance product. Before offering his service, the broker invests in his advice quality, which is assumed to cause increasing and convex costs.

The model described in this article implies perfect observability of brokers' advice quality by cedents. It is borne in mind that the results serve as a kind of benchmark: advice quality in the unregulated market is found to be suboptimal even in the limit of perfect observability. Therefore, unobservable advice quality will tend to be even worse. On the other hand, brokers have certain documentation obligations and are subject to a liability for wrongdoing. These measures are meant to be an incentive for brokers to be honest and give the best professional advice possible within their capabilities.

We break down the analysis into two parts according to whether a broker who is already in the market is subject to competition from potential new entrants. We obtain the result that an uncontested monopoly broker will offer less advice quality and charge a higher price than a benevolent social planner would choose in order to maximise social welfare. The outcome in the case with potential new entrants depends on the flexibility of the broker's advice quality and price once entry has occurred. However, the first best welfare level is never achieved as a market outcome in this case either.

The fact that the first best welfare level is never realised, irrespective of whether new entry may occur or not, raises the issue of regulation. The social optimum can only be achieved by regulating both advice quality and price at the same time. However, price may not be available as a policy instrument for regulation. In this case, even regulation of advice quality alone increases social welfare in the case of full flexibility of price and advice quality. The same may hold true if advice quality is inflexible, depending on the shape of the broker's cost function of investing in advice quality. However, if both variables are inflexible, regulation of advice quality alone no longer improves social welfare. Generally, the model can also be applied in the context of primary insurance brokers and retail clients. Altogether, the findings seem to support the EU's measures in order to regulate a minimum training level of insurance and reinsurance intermediaries. 


\section{Acknowledgements}

All views expressed in this article are those of the authors. They do not necessarily represent the views of and should not be attributed to Munich Re. An earlier version of this article was presented at the First World Risk and Insurance Economics Congress in Salt Lake City 2005. We thank participants of the meeting for useful comments.

\section{References}

Barrese, J., Doerpinghaus, H.I. and Nelson, J.M. (1995) 'Do independent agent insurers provide superior service? The insurance marketing puzzle', The Journal of Risk and Insurance 62(2): 297-308.

Barrese, J. and Nelson, J.M. (1992) 'Independent and exclusive agency insurers: A re-examination of the cost differential', The Journal of Risk and Insurance 59: 375-397.

Berger, A.N., Cummins, J.D. and Weiss, M.A. (1997) 'The coexistence of multiple distribution systems for financial services: The case of property-liability insurance', Journal of Business 70(4): 515-546.

Bertrand, J. (1883) 'Théorie Mathématique de la Richesse Sociale', Journal des Savants 67: 499-508.

Cummins, J.D. and VanDerhei, J. (1979) 'A note on the relative efficiency of property-liability distribution systems', Bell Journal of Economics and Management Science 10: 709-719.

Cummins, J.D. and Weisbart, S.N. (1977) The Impact of Consumer Services on Independent Insurance Agency Performance, New York, NY: IMA Education and Research Foundation, Glenmont.

Etgar, M. (1976) 'Service performance of insurance distributions', The Journal of Risk and Insurance 43: 487-499.

Gravelle, H. (1991) 'The welfare economics of controls on brokers' commissions', The Geneva Papers on Risk and Insurance 16(58): 3-19.

Gravelle, H. (1993) 'Product price and advice quality: Implications of the commission system in life assurance', The Geneva Papers on Risk and Insurance Theory 18(1): 31-53.

Gravelle, H. (1994) 'Remunerating information providers: Commissions vs. fees in life insurance', The Journal of Risk and Insurance 61(3): 425-457.

Grossman, S.J. and Hart, O.D. (1986) 'The costs and benefits of ownership: A theory of vertical and lateral integration', Journal of Political Economy 94(4): 691-719.

Hotelling, H. (1929) 'Stability in competition', Economic Journal 39: 41-57.

Joskow, P.L. (1973) 'Cartels, competition, and regulation in the property-liability insurance industry', Bell Journal of Economics and Management Science 4: 375-427.

Kim, W.-J., Mayers, D. and Smith Jr., C.W. (1996) 'On the choice of insurance distribution systems', The Journal of Risk and Insurance 63(2): 207-227.

Marvel, H. (1982) 'Exclusive dealing', The Journal of Law and Economics 25: 1-25.

Mayers, D. and Smith Jr., C.W. (1981) 'Contractual provisions, organizational structure, and conflict control in insurance markets', Journal of Business 54(3): 407-434.

Posey, L.L. and Tennyson, S. (1998) 'The coexistence of distribution systems under price search: Theory and some evidence from insurance', Journal of Economic Behavior \& Organization 35 : 95-115.

Posey, L.L. and Yavaş, A. (1995) 'A search model of marketing systems in property-liability insurance', The Journal of Risk and Insurance 62(4): 666-689.

Sass, T.R. and Gisser, M. (1989) 'Agency cost, firm size, and exclusive dealing', Journal of Law \& Economics 32: 381-400.

Schlesinger, H. and Graf von der Schulenburg, J.-M. (1991) 'Search costs, switching costs and product heterogeneity in an insurance market', The Journal of Risk and Insurance 58(1): 110-119. 
Seog, S.H. (1999) 'The coexistence of distribution systems when consumers are not informed', The Geneva Papers on Risk and Insurance Theory 24: 173-192.

Seog, S.H. (2005) 'Distribution systems and operating leverage', Asia-Pacific Journal of Risk and Insurance 1(1): 45-61.

Venezia, I., Galai, D. and Shapira, Z. (1999) 'Exclusive vs. independent agents: A separating equilibrium approach', Journal of Economics Behavior \& Organization 40: 443-456.

\section{Appendix}

Relative position of $s^{R}$ and $s^{C}$

The following graphs show simulation outputs of $s^{R}$ and $s^{C}$ for varying parameters of a family of cost functions of the form

$$
C(s)= \begin{cases}k(s-0.6)^{z} & \text { for } s \geqslant 0.6, \\ 0, & \text { otherwise. }\end{cases}
$$

It becomes apparent that $s^{R}$ is always larger than $s^{C}$, although the difference $\left(s^{R}-s^{C}\right)$ converges against 0 if $k$ grows large or $z$ becomes small. This shows that social welfare can always be increased at least slightly by regulating a minimum advice quality $s$ in the cases which have been simulated. However, the possible welfare gain decreases sharply in the limit of a large $k$ or a small $z$. Further parameter specifications for the simulations were $V_{A A}=100, V_{B A}=95$ and $p_{A}=70$ (see Figures A1-A4). 
44

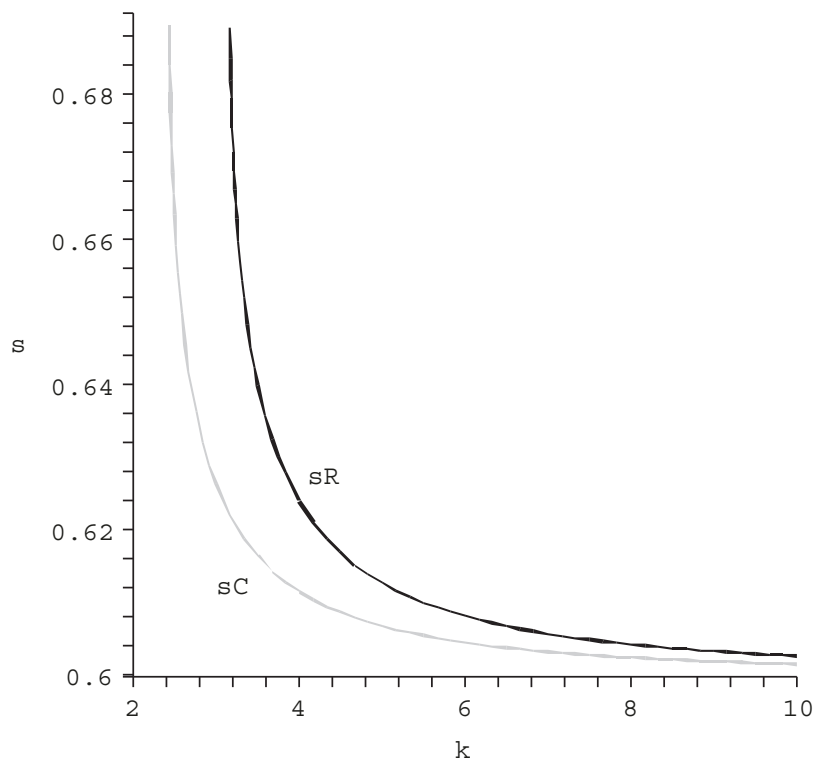

Figure A1. $s^{R}$ and $s^{C}$ for various $k$ with $z=1.5$.

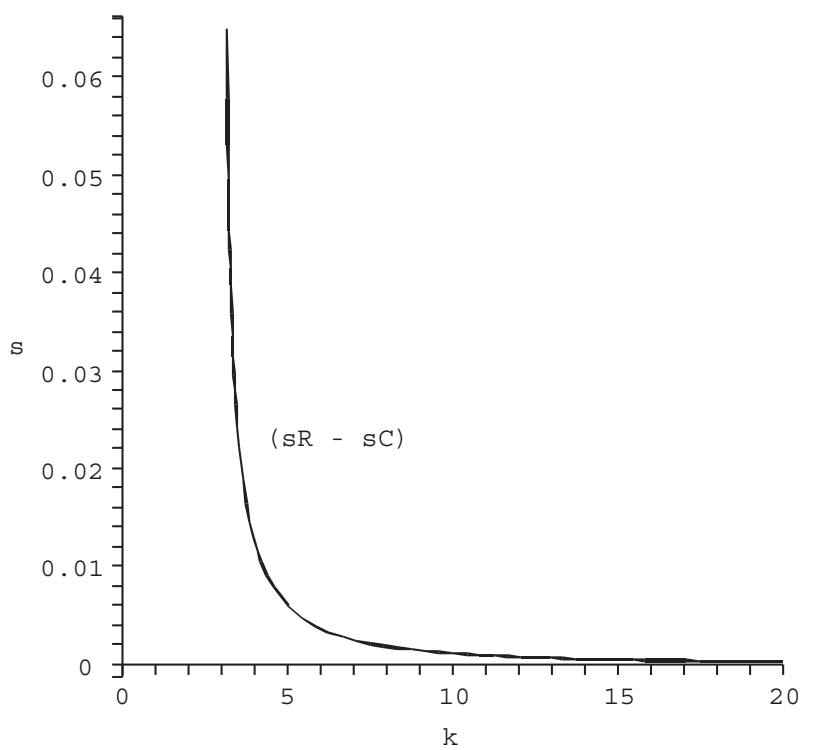

Figure A2. $\left(s^{R}-s^{C}\right)$ for various $k$ with $z=1.5$. 


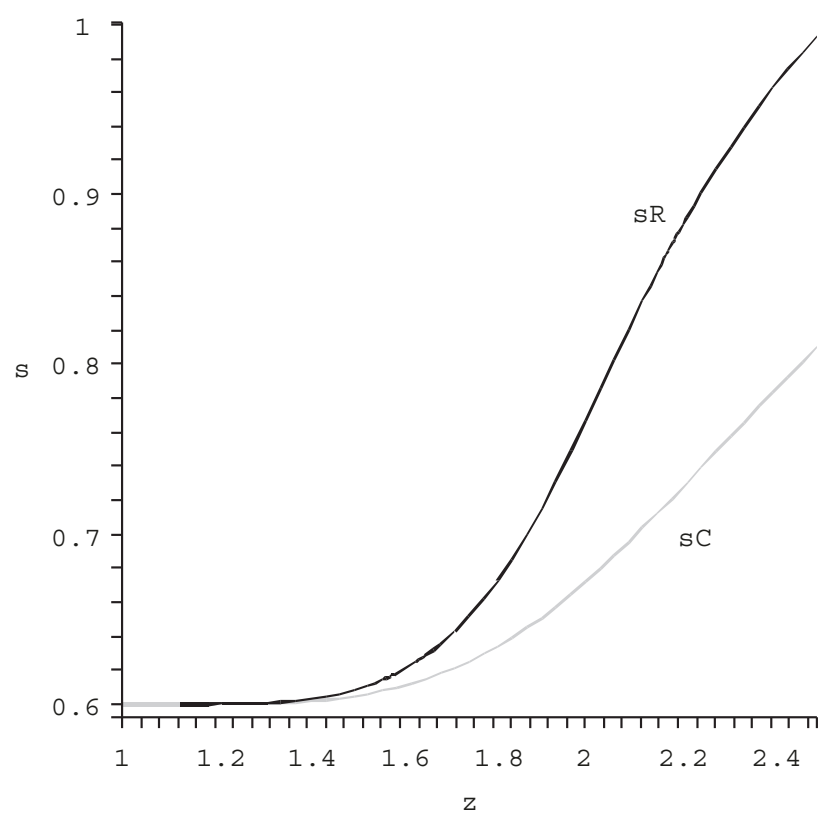

Figure A3. $s^{R}$ and $s^{C}$ for various $z$ with $k=6$.

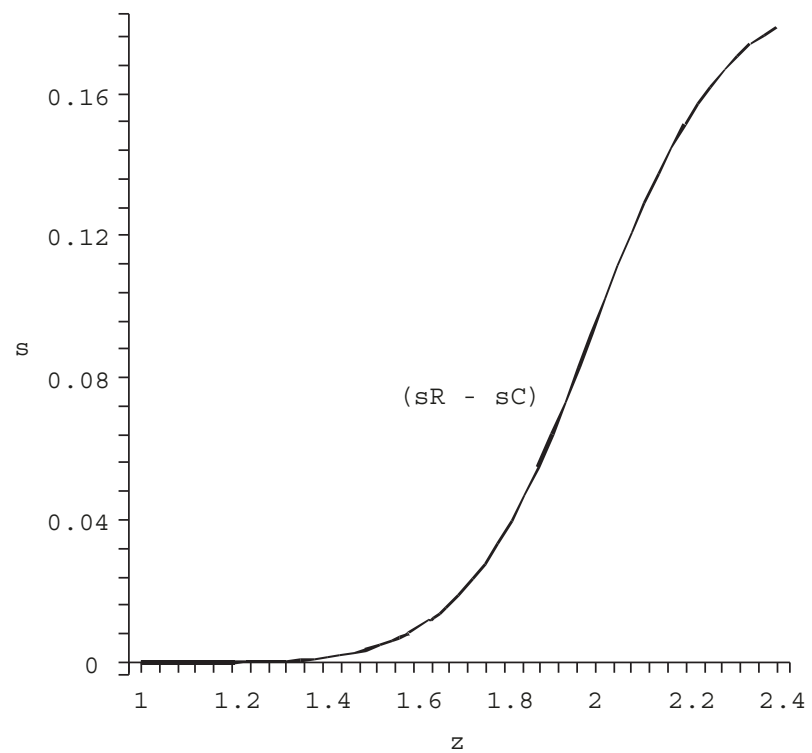

Figure A4. $\left(s^{R}-s^{C}\right)$ for various $z$ with $k=6$. 


\section{About the Authors}

Michael Sonnenholzner, Consultant Economic Research, Munich Re, Königinstrasse 107, 80802 Munich, Germany. E-mail: msonnenholzner@ munichre.com. An earlier version of this article was partly written while the author was a Ph.D. student at the University of Erlangen-Nurnberg. Financial support by the Staedtler Stiftung during this period of time is gratefully acknowledged. E-mail: msonnenholznera@munichre.com.

Sebastian Friese, Manager Corporate Strategy, Munich Re. Königinstrasse 107, 80802 Munich, Germany, external Ph.D. candidate of the Institute for Risk and Insurance. Leibniz University Hannover, Germany. E-mail: sfriese@munichre.com.

J.-Matthias Graf v. d. Schulenburg is the Director of the Institute for Risk and Insurance. Leibniz University Hannover. Germany. and Chairman of the Management Board, Kompetcnzzentrum Versicherungswissenschaften $\mathrm{GmbH}$, Hannover, Germany. E-mail: jms@ivbl.uni-hannover.de. 